\title{
The trade and circulation industry affects the mechanism and efficiency evaluation of regional economic development in China
}

\author{
Li Zhao \\ Shaanxi Academy of Governance, Xi’an 710000, China
}

Keywords: Trade and commerce; Regional economy; Influence mechanism; Efficiency evaluation

\begin{abstract}
In production and consumption, the trade and commerce industry plays the role of bridge and link, which is of great significance to the development of regional economy. Although the importance of commercial circulation in regional economic development has been reached, the impact mechanism and efficiency evaluation of the trade circulation industry are still inadequate. This paper mainly discusses the specific mechanism of regional economic development and the efficiency assessment method of trade circulation industry through the design of index system.
\end{abstract}

\section{Introduction}

Since the reform and opening up, the trade and commerce industry has developed rapidly and gradually become the supporting industry in the service industry. Commerce at the same time as a commodity market coupling of production and consumption of the intermediate links, in promoting production, guide consumption, promote upgrading of the industrial structure and promote the economic growth mode transformation plays an important role. Therefore, the research of the trade and commerce industry has gradually entered the field of view of scholars, and the mechanism and efficiency assessment of the trade and circulation industry in China's regional economic development is the most basic.

In the relationship between industry and economic development, contribution has always been one of the main measures, which mainly shows in economy and employment. Among them, the economic aspect refers to the main indicators that can be reflected in the relationship between trade flows and regional economic growth. At present, the regional economic contribution commerce shown in only about $10 \%$, compared with the developed countries contribute force obviously on the low side, commercial and trade circulation industry development in our country and developed countries there is a certain gap. However, according to the experience of trade and trade in developed countries, there is a great potential for the development of trade flow in China.

In the commercial circulation industry, the competition and monopoly of the industry can be reflected through the market concentration. The competition of commerce and trade in China is becoming more and more intense. In this competitive situation, the market concentration of China's trade and commerce industry is increasing. Standing in the perspective of the government, the rapid development of the commerce circulating industry in our country without the government's strong support, with the support of the government commercial and trade circulation industry in our country much enterprise scale is constantly expanding, the development is also very well. From the perspective of enterprises, China's commercial circulation industry still has a relative gap with developed countries in terms of market concentration and needs further development and improvement. As an important industry in the tertiary industry, commerce and trade circulation industry in our country has become one of the necessary link in the operation of modern market economy, the scope of its operations hit multiple industries in national economy, with a strong role in promoting the regional economy development. 


\section{The specific mechanism of the economic development of the region}

The mechanism of the influence of trade and trade on regional economic development. Regional economic development, its changes mainly reflected in the regional economic aggregate growth, scale expansion and structure optimization and upgrading, etc., is a period of an economic upgrading phenomenon. For regional economic development, the positive influence of the trade and commerce industry is mainly to promote its development from the lower level to the higher stage. The essence of regional economic development is the accumulation and qualitative leap of regional economy. The influence mechanism of regional economic development can be analyzed from two levels: quality and quantity.

Commerce to the influence of the level of regional economic development, commercial and trade circulation industry plays a linking role in the production and consumption segments, not only closely related with the social reproduction, but also can provide key guarantee for social economy running smoothly. According to the level of commerce to promote the development of social production, mainly comes from the interaction of production and consumption, the effect is not only beneficial to the increase of the gross domestic product (GDP) and the improvement of regional financial revenue, but also conducive to trade with the expansion of social employment, etc., these will promote the regional economy and the growth of the scale, promoting regional economy increasing, and the expanding scale of regional economy. Commerce qualitative to regional economic development level: the influence of commerce on the effect of regional economic development is mainly manifested in the regional economic structure, the adjustment of the economic growth pattern, optimization of the regional economic elements configuration and efficiency factors of regional economic upgrade, etc. The influence of economic structure is mainly manifested in the continuous adjustment and optimization of industrial structure, intra-regional demand structure and intra-regional trade structure. Among them, the industrial structure mainly refers to the proportion of three industries in regional economic development and structure, demand structure is mainly associated with the structure of residents in consumption demand, the trade structure is mainly related to the trade product structure, etc. In the influence of the element configuration, mainly working in commerce in the region, regional capital, technology, etc, the influence of these elements in the regional industry, industry and the transfer between the rural and urban areas as commerce the prominent role in regional economy development mechanism. , the influence of factors on efficiency in commercial and trade circulation industry in the region production elements unit capacity, the influence of the flow of commerce through the role and influence, to constantly improve the capacity factors of regional units. The development of the trade and commerce industry is conducive to the realization of the breakthrough of the regional economy to the original economy, so as to further develop the regional economy and promote the upgrading of the regional economy.

\section{Construction and evaluation of the efficiency index system of trade circulation industry}

The indicators included in the output index have a value of Y1 (100 million RMB), which is mainly reflected in the level of development of trade and trade. Y2 (\%) index and Y3 (\%) index of logistics distribution are mainly reflected in the chain of trade and trade. The indicators included in the input indicators have the index of X1 (10,000 people). RMB X2 (100 million RMB) index of fixed assets investment in circulation industry; Expenditure on R\&D budget: X3 (10,000 RMB); Internet broadband access port number X4 $(10,000)$ index; The number of commodity trading market of more than 100 million RMB $\left(x^{* 5}\right)$ index; Freight volume X6 (10,000 tons) index; Highway mileage X7 $(10,000 \mathrm{~km})$ index; Railway mileage of X8 (10,000 km) index; Energy consumption X9 (tons of standard coal / 10,000 RMB) index.

GRA to complex system internal change trend and the relationship between research and processing, the starting point is mainly based on the completeness and uncertainty, under this kind of method can quickly solve the index quantification and difficult statistical the two outstanding problems that human influence could be eliminated at the same time, make the results more objective and accurate. 
The GRA model usually consists of four steps in the specific analysis process: in the first step, not only the reference sequence is determined, but also the comparison sequence. In the second step, you need to give relatively standardized processing to the index sequence, the transformation of raw data to the dimensionless values, the initial value is changed into comparison with the transformation of the mean is the commonly used processing methods. The third step is to calculate the correlation coefficient:

$$
\zeta \mathrm{i}(\mathrm{k})=\frac{\min _{\mathrm{i}} \mathrm{k}|\mathrm{Ck}-\mathrm{Cki}|+\rho_{\mathrm{i}} \mathrm{k} k \mathrm{k}}{|\mathrm{Ck}-\mathrm{Cki}|+\rho_{\mathrm{i}}^{\max } \max |\mathrm{Ck}-\mathrm{Cki}|}
$$

In equation (1), zeta I $(\mathrm{k})$ refers to the correlation coefficient between the KTH index and $\mathrm{k}$ the optimal index in the it scheme; Does $\{C\}=\left\{C_{1}, C_{2}, \ldots, C_{n}\right\}$ means a reference sequence; $\{C\}=\left\{C_{i 1}\right.$, $\left.\mathrm{C}_{\mathrm{i} 2}, \ldots, \mathrm{C}_{\mathrm{n}}\right\}=$ means to compare sequences; Rho is the resolution coefficient, rho is the same as the normal value of 0.5 . In the fourth step, the grey relational degree is mainly calculated. On grey correlation coefficient values are not only presents the trend of more and usually more fragmented, will affect effectiveness of information collection, usually the average correlation coefficient, its value is the grey correlation degree.

$$
\mathrm{ri}=\frac{1}{\mathrm{n}} \sum_{\mathrm{k}=1}^{\mathrm{n}} \xi_{\mathrm{i}}(\mathrm{k})
$$

The closer the correlation is to 1 , the stronger the correlation. Correlation is usually associated with $>0.6$, which is usually associated with $>0.85$.

The DEA is an analysis of the relative effectiveness or benefit of the "department" in the application of mathematical programming model. These "departments" or "units" can have multiple inputs and outputs. For the effectiveness and scale of decision making unit, DEA not only has evaluation or ordering effect; moreover, it can realize the reasons for the node of various decision units, and put forward the improvement direction on this basis.

For modern commerce, can there are many factors that can influence to its, and these factors have different influence degree, should be carried out from the input index of the sorting and filtering, to extract the main factors. The grey relational model is used to extract the main indexes. In order to improve the comparability of data, standardized processing was carried out by SPSS software in the grey relational analysis process, and the correlation degree was determined according to the result size.

Can be seen from the dynamic change trend of the national average, commercial and trade circulation industry in China from 2014-2015 or regardless of overall efficiency of the tendency of technical efficiency are first fall after rise, but the scale efficiency are shown to rise year by year. Specific to the east and west regions, the comprehensive and technical efficiency of the eastern region shows that the first after the first drop, the scale efficiency is shown in the first promotion. In the central region, the efficiency of the three aspects is decreasing first and then rising. The comprehensive and scale efficiency of the western region shows that the technical efficiency has been decreasing. Based on regional differences, the eastern region is higher than the central and western regions regardless of comprehensive efficiency or technical efficiency or scale efficiency. Between 2014 and 2015, the central region of scale efficiency significantly exceeded the western region; In terms of comprehensive and technical efficiency, the central part of 2014 was lower than the western region, and 2015 was higher than the western region. From the provincial differences between the eastern region of Beijing, Tianjin, Shanghai, Jiangsu and Guangdong and Hainan, the central region of Guangxi, Guizhou, Yunnan, and Inner Mongolia region superiority in the development of commercial and trade circulation industry is higher, in the aspect of resources with a combination of more reasonable structure. In terms of its input and output technology efficiency, the ten provinces 
and cities have not been engaged in redundant and insufficient output, and at the same time, they are at the best scale.

Commerce service of capital per capita growth and manufacturing output per capita growth, productive capital stock per capita growth, and there is a long-term stable relationship per capita growth rate of human capital, and this relationship is interactive. The result of the analysis of the impulse response is that the growth of the capital service of the commercial circulation industry brings a certain end impact effect to the manufacturing development, which can drive the growth of manufacturing output sustainably. In the first five years, the first 10 years, in the first 20 years, the total response of the manufacturing industry to the capital services of the trade and commerce industry was $0.009979,0.016947,0.02453$ and 0.027777 respectively. The increase in the increase of manufacturing value of the manufacturing industry has also had some impact on the development of capital services. In the first five years, the first 10 years, the first 20 years and the first 30 years, the accumulative response of capital services reached 0.098906, 0.104947, 0.109826 and 0.111909 respectively. In combination, the impact of the growth of capital services in trade and commerce has a lasting positive effect on the improvement of manufacturing output, but its effect is not obvious. In relative terms, the fluctuation of manufacturing output has obvious effect on the improvement of the capital service level of tradable trade.

\section{Summary}

Regions in our country should strengthen the exchanges and cooperation, especially in the central and western regions should strengthen cooperation with the eastern region and the developed areas of the world trade, the experience of developed regions commerce development. China should also gradually establish a unified market for trade and commerce, improve the circulation system of commerce, and give full play to its role in linking production and consumption. For regional commerce hardware environment conditions should increase investment, actively promote the modern circulation mode, explore new formats, innovation model of commodities interflow, provide sufficient guarantee for the development of commerce. In addition, our country should strengthen the control and guide the commerce circulating industry, optimize the regional circulation resource configuration, narrow features three major regional circulation efficiency gap and promote the development of commercial and trade circulation industry in our country to realize balanced, comprehensive, promote balanced development of regional economy.

\section{References}

[1] Barbara Rudolf, MathiasZurlinden. Measuring Capital Stocks and Capital Servicesin Switzerland. (Swiss Society of Economics and Statistics, 2009), p. 61-105.

[2] DECD. Measuring Capital DECD Manual-Measurement of Capital Stocks. (Consumption of Fixed Capital and Capital Services, 2001), p. 1-131.

[3] Young,Alwyn.Gold into Base Metals: Productivity Growth in the People’s Republic of China during the Reform Period. (Journal of Political Economy, 2003), p. 1220-1230.

[4] Liu M, Liu F, Zhao Y, et al. China's Current Development Status and Prospect of Foxtail Millet Trade and Industry. (Proceedings of Selected Articles of 2013 World Agricultural Outlook Conference. Springer Berlin Heidelberg, 2014), p. 53-67. (In Chinese)

[5] The organization of economic cooperation and development. Capital measurement manual: capital consumption and capital service measurement. (Beijing: China statistics press, 2004). (In Chinese).

[6] Guo qingwang, jia junxue. Estimation of total factor productivity in China: 1979-2004. (Economic research, 2005), p. 51-60. (In Chinese) 
[7] Mu G, Zhang X, Gao S, et al. Problems Analysis and Future Prospect of Chinese Retail E-commerce. (Proceedings of the 2013 International Conference on Management of e-Commerce and e-Government. IEEE Computer Society, 2013), p. 7-10. 